\title{
Aportacions a la classificació de llegendes de moros de la serra de Tramuntana (Mallorca)
}

\author{
Tomàs Vibot Railakari \\ Universitat de les Illes Balears \\ tomasvibot@gmail.com
}

RESUM

La narrativa popular amb els moros com a protagonistes en les terres de la serra de Tramuntana de Mallorca és prou abundosa i rica, tal com ho demostra la gran quantitat de relats inclosos en els reculls de llegendes publicats des del final del segle XIX fins a pràcticament els nostres dies. Tot i que una part important del gruix d'aquests relats pertanyen al mode realista, comptem amb un interessant cabal de llegendes (mode fabulós) que avui dia no ha estat objecte de classificació. Partint de la proposta de classificació dels gèneres etnopoètics d'Heda Jason (2000), es destrien i analitzen totes aquelles llegendes que tenen com a protagonista (o coprotagonista) la figura del moro, un mot que dins l'imaginari popular s'identifica amb musulmà $i$, generalment, es presenta amb unes connotacions negatives. Tot $i$ això, el llegendari mostra altres caires d'aquest personatge $i$, per aquest motiu, es pot afirmar que resulta una figura prou diversa i rica dins els materials folklòrics.

PARAUles ClAU

llegendari; Mallorca; moros; cristians; serra de Tramuntana; tipologies llegendàries

\section{ABSTRACT}

Popular Mallorcan narrative is rich in folktales featuring Moors as protagonists in the Serra de Tramuntana mountains, as evidenced by the great number of stories included in the collections oflegends that have been published since the late nineteenth century almost up to the present day. Although many of these stories may be classified as realistic, there is an interesting set of 'fabulous' legends that has still to be classified. Using the classification of ethnopoetic genres proposed by Heda Jason (20oo), the article analyses all those legends that have as protagonist (or co-protagonist) the figure of the Moor, a word that is identified with Muslim in the popular imagination and that generally has negative connotations. However, the legends show other aspects of the Moor's character, thus making him quite a diverse and rich figure in the Mallorcan folklore tradition.

KEYWORDS

legends; Mallorca; Moors; Christians; Serra de Tramuntana; legend typologies

Rebut: I9/OI/2OI8 | ACCEPTAT: 9/O4/2OI8 


\section{Objectius}

La finalitat del següent treball és aportar una proposta de classificació de les llegendes protagonitzades (o coprotagonitzades) per moros en el marc de la serra de Tramuntana de Mallorca. Si bé les rondalles han estat objecte d'estudi i classificació —n'hi ha prou d'esmentar l'Índex tipològic de la rondalla catalana, de Carme Oriol i Josep M. Pujol (2003) o la reedició crítica de les Rondaies mallorquines d'en Jordi des Racó, a cura de Josep A. Grimalt (2006-20I3), entre molts altres treballs-, les llegendes no han estat mereixedores de tants esforços per part dels folkloristes. ${ }^{\mathrm{I}}$

Com a mètode d'anàlisi ens hem basat en la proposta de classificació modal i de gènere d'Heda Jason continguda al treball Motif, type and genre (2000). El corpus analitzat són els textos publicats en els diferents reculls generals (Rondalles mallorquines d'en Jordi des Recó, Llegendes de les Balears, etc.) i locals (Recull de narrativa popular. Puigpunyent-Galilea, Llegendes de les terres de Lluc, etc.). Cal avançar ara aquí que molts dels textos que apareixen a les publicacions com a llegendes en realitat corresponen al mode realista i, per tant, els hem descartat (són citats a l'apèndix). El gruix d'aquest material no inclòs, a més a més, es troba dins allò que s'ha vingut a qualificar com a llegenda històrica, de la qual Josep Maria Pujol afirma que «no són folklore, perquè el seu context no és el de la interacció d'un petit grup sinó el de la crònica medieval, renaixentista i barroca» (20I3: 286).

\section{Els moros en el folklore mallorquí}

El Diccionari català-valencià-balear defineix moro com a «nadiu de l'Àfrica septentrional, de sang àrab o bereber; per extensió, Mahometà». Si ens hem de basar en termes estrictament filològics, el mot moro designava en època romana els habitants de Mauritània, però des de l'època medieval fins a l'actualitat a les terres de parla catalana s'usa per anomenar de manera genèrica tots els musulmans.

Per a la cultura popular illenca el significat d'aquest mot va molt més enllà, gairebé sempre en un sentit pejoratiu. El mateix diccionari, tot deixant de banda alguns significats molt puntuals que fan referència a objectes o plantes (mà de moro, figa de moro, etc.), n'apunta uns quants exemples: usat com a adjectiu, té un sentit de «mal cristià» i, quant a fraseologia, hi apareixen fórmules com posar moro de jornals (obligar els escaraders malfeiners a treballar alguns jornals), fer moros (fer trampes) o passar una vida de moros (tenir una vida molt amarga).

L'origen d'aquesta percepció negativa té fondes arrels històriques. Les més pròximes a la nostra cultura estan basades en l'antagonisme religiós i de poder, especialment a partir de l'ocupació de la península Ibèrica el 7II dC (Al-Àndalus versus regnes cristians) i en les contínues ràtzies que patien les costes illenques des del segle XIII fins al XVIII. Després de la conquesta de Jaume I (I229), els mallorquins sempre han identificat (i continuen fent-ho) qualsevol persona de pell morena i de religió islàmica com a moro, tot i que en molts de casos l'així assenyalat sigui oriünd d'altres zones de la Mediterrània (sud, oriental, fins i tot de l'Orient Mitjà).

I Si bé en els darrers anys han aparegut nombrosos reculls de llegendes arreu de Mallorca, generalment de caire local o centrats en personatges llegendaris (rei En Jaume I, sant Vicenç Ferrer, el Comte Mal), el treball de classificació per gènere i tipus encara resta per fer. Les dificultats que acull l'estudi de la llegenda ja fou denunciat per Wayland D. Hand l'any I965, quan en digué: «For the systematizer, folk legends seem endless in bulk and variety, and they are often so short and formless as to defy classification» (I965: 440). 
En línies generals, per a l'imaginari col-lectiu mallorquí, el mot moro ha format part del mateix camp semàntic que enemic (amb tot el que això comporta de ser perillós, tenir males intencions, ser poc de fiar, fins i tot presentar-se com un ésser misteriós).

En general, al folklore mallorquí el mot moro s'ha utilitzat per designar els andalusins (incloent-hi els que habitaren Mayurqa abans del rei Jaume I), els esclaus derivats de la conquesta i d'èpoques posteriors, els pirates barbarescs (Algèria) que posteriorment atacaren les costes i embarcacions cristianes i, finalment, els otomans que a partir del segle xvi assetjaren sense pietat les Balears. En aquest sentit s'expressa Bartomeu Prohens en l'estudi Inquisició i bruixeria a Mallorca:

A Mallorca els musulmans, o «moros», sempre tingueren per als mallorquins un doble simbolisme. Per una part la gent era conscient que les illes foren antigament un territori islàmic [...]. Per altra part la pirateria sarraïna era tan freqüent que la gent sabia que la mar i la costa eren llocs perillosos (I995: I22).

Cal dir, però, que també es dona una altra dimensió folklòrica del concepte. Quan es parla del temps dels moros es fa referència a una època quasi mítica, és a dir, situada en eres pretèrites abans de l'existència del nostre món (fundat pel monarca Jaume I). Per tant, per a l'imaginari popular mallorquí hi ha dos temps històrics contraposats: el temps dels moros (difús, misteriós, fosc, fins i tot extravagant) i d'ençà el rei En Jaume (el nostre temps).

Les narracions etnopòetiques protagonitzades (o coprotagonitzades) per moros dins el marc de la serra de Tramuntana ${ }^{2}$ són especialment nombroses, tant que pràcticament no hi ha cap municipi litoral que no en tingui almenys una. Algunes, fins i tot, en presenten moltes variants i versions, tantes quasi com recol-lectors o reescriptors. Aquesta abundor té una clara explicació històrica atès el veïnatge de la serra amb la mar i l'existència de ports i cales on les ràtzies de pirates o corsaris eren freqüents fins a finals del segle xviII. Per tant, els moros varen formar part de l'univers quotidià o pròxim de la gent que va viure en aquella època.

S'ha de dir, però, que no totes aquestes llegendes tenen com a protagonista el moro que saqueja els pobles i les possessions (un enemic), sinó que també n'hi ha un grup -en nombre inferior- on el protagonista es converteix en un exemple moral, enfrontat amb el mal cristià (qui finalment surt perdent), o també apareix com el portador d'un coneixement profund, gairebé màgic, sobre les lleis de la naturalesa (saber ocult o vetat als cristians, però del qual es beneficien).

\section{Classificació de les llegendes}

Per llegenda entenem un relat situat en el mode fabulós, submode numinós ${ }^{3}$ que té per missió revelar l'ordre del món amb la voluntat de reglamentar la conducta

2 Entenem la serra de Tramuntana com l'àrea delimitada en la declaració de la Serra com a Patrimoni de la Humanitat (2OII), que inclou (totalment o parcial) els denou municipis d'Alaró, Andratx, Banyalbufar, Bunyola, Calvià, Campanet, Deià, Escorca, Esporles, Estellencs, Fornalutx, Lloseta, Mancor de la Vall, Pollença, Puigpunyent, Santa Maria del Camí, Selva, Sóller i Valldemossa.

3 Segons Jason, «in this mode man confronts a fabulous world which is part of the society's belief systems» (2000: I38). 
humana. Té aparença de realitat, motiu pel qual resulta creïble (Oriol 2002: 69). A partir de la classificació de Jason, hi identifiquem llegendes sacres, etiològiques, màgiques i demòniques.

\subsection{Llegendes sacres}

Segons Jason, una llegenda sacra és aquella en què «the sacred power of the official religion solves the conflicts in the narrative and the problems the narratives poses. This legend is set in the mode of the sacred, in historical and eschatological epochs ant in all spaces of "this" and the "other" world but not in mythic space» (2000: I45). Dins aquest grup, hi encabim la llegenda hagiogràfica, és a dir, una llegenda protagonitzada per un sant.

Dins el conjunt de les llegendes sacres, els moros es presenten - a excepció de dos casos- com els enemics no sols de la població mallorquina, sinó també de la vertadera fe. Per tant, en cap cas els atacants no es poden sortir amb la seva i en canvi sí que ho poden fer els cristians atacats. El gruix d'aquests relats és protagonitzat per la Mare de Déu de Lluc, primer referent de la fe a Mallorca. Rafel Busquets, en el seu Llibre de la invenció i miracles de la prodigiosa figura de Nostra Senyora de Lluc (I684), ${ }^{4}$ recull el capítol titulat «Nostra Senyora Santíssima allibera molts vaixells de tempestats i corsaris» (I989: I3I-I42), on es relaten alguns miracles produïts al segle XVII per la Mare de Déu sobre mariners devots (mallorquins i àdhuc forans). Feliu Reynau, natural de Marsella, veient-se abordat per dues galiotes de Trípoli, invocà la Verge i es produïren diversos miracles:

la primera fonc que els moros mai pogueren aferrar amb son vaixell; la segona que en dos arcabussos de pedra, que els corsaris els apuntaren i els haurien morts a tots, estant tan a prop, mai l'espira inflamà la pólvora; i lo mateix succeí en dos mosquetons i escopetes amb que també els apuntaren. La tercera cosa miraculosa fonch que en els dos dies que durà aquella envestida, mai arribaren els corsaris a apoderar-se d'ells (I989: I32).

Tot seguit es relaten altres miracles obrats davant l'amenaça imminent de moros: l'esclau mallorquí Vicenç Balaguer, amb cinc cristians més, pogué fugir de Barbaria gràcies a invocar la Mare de Déu. El patró Damià Duran, arrossegat per una tempesta davant la badia de Tunis, pogué salvar-se de tres vaixells de moros que s'emproaven cap a ell i amb vent a favor, tot després d'invocar «de tot cor Nostra Senyora i Lluch» (I989: I37) i prometre una peregrinació al santuari. El patró Pere Cavaller, en sengles trajectes entre Mallorca i València, es topà amb dues galiotes mores i se'n pogué sortir gràcies al prec devot a la Mare de Déu. El mateix succeí al patró Miquel Femenia, que venia de València i feu promesa de visitar el santuari de Lluc «si escapaven dels moros», cosa que ocorregué gràcies a «un impuls del cel» (I989: I40). L'esclau mallorquí Aloi Martorell treballava en la construcció d'una fortalesa a Turquia i després d'invocar la Verge mallorquina liderà una rebel-lió contra els captivadors i pogueren fugir en una galera amb la qual

\footnotetext{
4 És necessari apuntar que el mot invenció contingut al títol d'aquest recull de miracles fa referència, tal com expliquen Gabriel Camps i Gabriel Seguí (20I0: 9), «a la construcció d'un relat etiològic sobre la imatge de la Mare de Déu de Lluc i, secundàriament, sobre el seu santuari, per explicar el poder religiós de la imatge i la puixança del seu lloc de culte». Cal entendre'l, per tant, en el sentit de descoberta o trobada.
} 
arribaren a Mallorca. Finalment, el patró Bernat Puigserver, davant els Set Caps, es topà amb dues galiotes d'Alger. Invocaren «el Sant Crist d'Alcúdia i Nostra Senyora de Lluch» i a l'instant «veren, a l'aire, a la part de ponent dues columnes de color blau i damunt elles dues imatges, de les quals una demostrava ser la del Sant Crist i l'altra la de Nostra Senyora de Lluch» (I989: I4I).



Mare de Déu de Lluc.

Els dos relats, però, més colpidors es troben en el capítol titulat «Ntra. Senyora Santíssima de Lluch defensa la seva Santa Casa de la invasió dels moros» (I989: I05-IO9). El primer, esdevingut el dia de Sant Mateu de I569, desembarcaren 300 moros al torrent de Pareis i assaltaren diverses finques, on varen fer un gran nombre de captius. Un home, després d'invocar la Verge, se'n pogué defensar i fugir. A partir d'ençà, cap moro no ha pogut passar del Clot d'Albarca, un espai fronterer a Lluc, ja que s'hi va crear una mena de barrera miraculosa. El segon, situat el dia de Sant Joan Baptista de I663, narra com un estol de moros arribà davant el santuari i és defensat per «dos joves ben plantosos, desconeguts» (I989: I07), que després s'identificaren com a dos àngels. Aquesta llegenda, tot gràcies a la força argumental, ha estat versionada per Gabriel Janer Manila, amb el títol «Àngels amb espases defensen la Santa Casa contra els moros» (I984: 37-39).

L'argument de la marededeu trobada, tan repetit dins el món cristià, també és present en dues figures. Curiosament, en ambdós casos, qui localitza les figures és un esclau moro amb aquestes característiques: minyó (innocent, per tant), batejat (adscrit a la vertadera fe) i dins el context de la conquesta de Mallorca de I229.

En el cas de la Mare de Déu de Lluc, la primera versió documentada es troba en el capítol introductori de l'abans esmentat Llibre de la invenció i miracles de la prodigiosa figura de Nostra Senyora de Lluc: un infant moro, batejat amb el nom de Lluc, fent de pastor per la muntanya, topa la figura de la Verge sobre unes penyes tota envoltada «de resplandors celestials» (I989: 62). Ho conta a un monjo de l'orde de Sant Bernat, que, després de veure-ho amb els propis ulls, avisa les altes autoritats de l'illa, les quals donen ordre d'aixecar un oratori en aquell lloc. Aquí el relat recull la manifestació de la Providència divina que, meravellosament, ha 
volgut que hi aparegués la imatge de Nostra Dona en un lloc concret (un bosc a les muntanyes més altes de Mallorca), a un personatge concret (un nou fidel net de cor) i amb una finalitat concreta (ser el centre espiritual i de pelegrinatge marià de Mallorca). Si bé la figura del minyó moro no és l'única protagonista, sí que esdevé un element central, ja que la fe sincera té la recompensa de la visió celestial.

Atesa la importància d'aquesta llegenda dins la cultura de Mallorca, són moltes les versions d'aquest relat, les quals solen portar el títol genèric de «La trobada» (Janer I984; I999) o «La troballa» (Ordinas-Ordinas-Reynés I998).

El mateix argument apareix al relat de la trobada de la Mare de Déu de Lloseta (dita també del Cocó), encara que amb una variant: la figura, localitzada vora un cocó del torrent per un pastor moro convertit al cristianisme, és traslladada per les autoritats a l'església de Robines. L'endemà torna a aparèixer al mateix indret; novament és duta a Robines però, malgrat trobar-se reclosa dins una caixa, és descoberta de nou en el torrent, cosa que s'interpreta com una voluntat divina que sigui aixecat un oratori per venerar-la-hi..$^{5}$ Aquesta llegenda de la marededeu trobada es troba vinculada a la tradició del didalet, uns foradins a la roca (fets per la Verge) que curen els padrastres. Just a la vora hi ha també la pica de la Mare de Déu, que segons tradició és on rentava la roba del Bon Jesús.

Fora també de l'àmbit de Lluc, trobem el cas de la invocació a un sant per tal de no ser capturat per un estol de moros a Estellencs. El relat «Es desembarch des Moros» fou publicat l'any I895 per l'Arxiduc Lluís Salvador al seu tom de Rondayes de Mallorca. Tot i que el mode imperant és realista, el miracle es produeix al si de la narració, només sobre l'únic personatge que serva la fe i la invoca en el moment oportú. Els altres dos estellenquins seran víctimes d'un destí fatal.

\subsection{Llegendes etiològiques}

Jason defineix les llegendes etiològiques de la manera següent:

Legend, explaining the origin of certain secondary traits and properties of nature and human society, and various proper names (etymological legends). The action of the tale may be evaluated in the framework of the sacred legend's moral code. This legend is set in the mode of the sacred but stands midway between sacred legend and the myth; it is set in a quasi-mythic epoch at the beginning of "human (historical)" time and plays on the stage of "this world" (2000: I46). ${ }^{6}$

El context d'una època quasi mítica a què fa referència Jason es constata especialment en dues llegendes de la serra de Tramuntana. La primera, ubicada en la zona nord de la serra, concretament a la partió entre els termes d'Escorca i Pollença, se situa l'antiga alqueria d'Ariant, on s'ubica la llegenda titulada genèricament «El Purgatori d'Ariant». Es tracta d'un relat on predomina la raó etiològica, atès que explica l'origen —dels temps dels moros-d'unes grans formacions de roca. Un

\footnotetext{
5 Existeix una variant que diu que durant unes festes de Nadal la imatge aparegué a un esclau moro dins unes cavalleries. Aquesta tradició tingué una certa força, ja que fins i tot s'hi vincularen uns goigs que arrenquen dient: «Un nou convertit entrà / dins el sobredit estable / y un resplandor inefable / de repente lo espantà».

6 Per completar aquest apartat ha estat també molt útil la classificació que proposa Carme Oriol al treball «Le classement des récits étiologiques catalans» (2013).
} 
dels primers textos on es recollí aquest relat és en forma de poema, signat pel poeta i batle pollencí Ramon Martorell Bennàssar el maig de I922.7 L'arrencada presenta aquestes roques disforges i misterioses: «Amagat dins la muntanya / trobareu un roquissar, / que té la figura estranya / dels focs follets d'un fossar.» Segons la primera versió que en va fer Gabriel Sabrafin, al seu llibre Mallorca: leyendas, tradiciones y relatos (I980: 85-86), la princesa Guldana -famosa per sa bellesa i les festes que organitzava - vivia al palau d'Ariant. Els que la gaudien eren convertits en estàtua de pedra. Omar, un nan contrafet, desitjava secretament Guldana i se'n volia venjar. Durant una de les festes, cremà el palau i tallà el cap a la princesa. Fugint del foc i amb el cap sota el braç, es despenyà a la mar. Les restes del palau es convertiren en un bosc de roques i penyals, conegut com el Purgatori d'Ariant. El mateix autor en va fer una segona versió (2002) on assegura que els informants de la contrada apunten que aquell indret es deia un temps el rafal de les Maleses, tot fent referència a aquell tràgic episodi. Una de les versions més reeixides, però, fou publicada per Caterina Valriu (2009), amb el títol «Gunara i el purgatori d'Ariant».

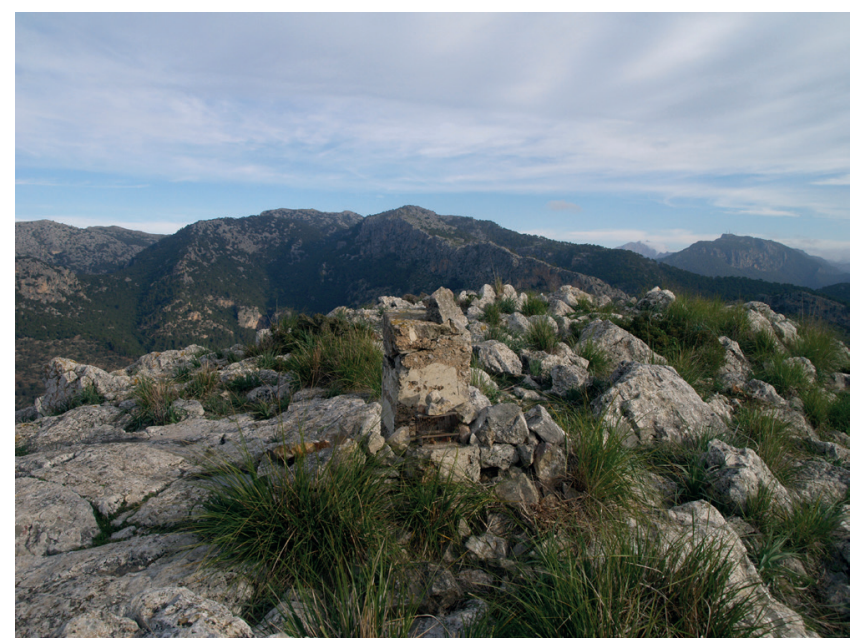

Puig de na Fàtima (Puigpunyent).

Dins el context d'abans de la conquesta, també trobem la llegenda titulada «La mora de Son Tries», situada a l'alqueria d'Alcàsser (Esporles), dita avui Son Tries. Fou publicada el 1996 per Llinàs i Martí i explica per què la taula de pedra de la font de Son Tries de Dalt en un dels cantells conté el relleu misteriós d'una cara.

En territori pollencí, sota els dominis del Castell del Rei, roman el topònim Can Canten i Dormen, nom que ens remet a una llegenda local versificada pel poeta Miquel Costa i Llobera entre el I3 i el I7 d'octubre de I9O2 (veié la llum el

7 Avui dia es coneixen poques dades biogràfiques de Ramon Martorell Bennàssar, Sionet. L'any que redactà el poema (I922) tenia uns 59 anys (per tant, es dedueix que nasqué cap al I863). Políticament va ser un declarat maurista i durant la seva batlia fou l'impulsor de la galeria dels Fills Il-lustres de Pollença que hi ha a l'Ajuntament. En l'àmbit oral es diu que el poeta Miquel Costa i Llobera encunyà l'expressió sionesc per definir actituds formalment exagerades i populistes. El poema apareix publicat al web Toponimia Mallorca < www.toponimiamallorca.net>, però no se'n cita la procedència. 
mateix any al seu volum Tradicions $i$ fantasies amb el títol «La ribera de Canten i Dormen»). En aquest cas ens situem en el context de la conquesta, quan un grup de sarraïns fugí dels cristians en una galiota. El motiu etiològic rau en el fet que encara se sent per aquella costa, especialment els dies de boira, els cants de les ànimes dels moros que remen (la resta mentrestant dorm), els quals romanen en una mena de limbe en forma de nigul. El seu cant, com el de les sirenes, fa perdre el rumb dels navegants que s'hi senten atrets. Posteriorment, aquesta llegenda fou recollida de boca de Joan Alsina (de Vilassar de Mar) per Joan Amades (I950: 869). Una de les darreres versions publicades és la de Caterina Valriu (2009). El topònim és ben viu, així com la llegenda, especialment dins l'àmbit mariner. Una possible explicació de l'aparició de l'encapçalament can és la relació que té amb el relat, com a indret habitat per les ànimes en pena (Valriu-Vibot 2005: I38).

Tot i que d'una manera força indirecta, podem encabir dins la classificació etiològica la llegenda «Presa del castell d'Alaró» recollida per Andreu Ferrer (2009) de boca de Miquel Sal. Seguint el mateix argument que «De com el rei en Jaume va prendre es castell d'Alaró» d'Alcover (I976, V: IO8-I09), descriu com els moros es llançaren daltabaix del castell dins alfàbies, i com varen morir tots gràcies a l'enginy d'un pastor. Ara bé, la versió publicada per Ferrer es troba encapçalada per aquesta explicació: «Diuen que damunt es castell d'Alaró, dins lo que era antigament jardí, hi ha una pedra semblant a una cadira i la gent l'anomena sa cadira del Rei Moro. Allà s'hi asseia sempre el principal dels moros» (2009: 26). A tall d'anècdota, és interessant posar l'accent no sols en l'explicació de l'origen de la cadira, sinó també en l'aparició d'un jardí, espai de profunda tradició nord-africana basada en els riads dels palaus àrabs.

En aquest mateix ordre etiològic — encara que ara dins el context de les ràtzies dels segles XVI i XVII-, s'hi poden encabir dues llegendes: «Es pastó d'es pou de ses Basses», publicada al volum de Rondayes de Mallorca de l'Arxiduc (I982: I87-I9I), on es dona l'explicació de per què l'amagatall d'un andritxol perseguit pels moros es diu la cova d'Escata Pa; i «Sa taula des moro», explicada per Joan Font Joan Toni a Catalina Calafat, Miquel Àngel Llauger i Joan Manuel Pérez (I985: 75). Es tracta d'una roca planera situada dins la mar on els moros posaren la campana de la parròquia després de saquejar el poble. Segons aquest informant, els banyalbufarins varen haver de llençar molts de litres d'oli a la mar per tal d'aplanar-la i així poder tornar la campana a terra.

Per acabar, cal esmentar que en alguns reculls apareixen textos que s'inscriuen en el context etiològic (gairebé molts es podrien qualificar d'etimològics) però que presenten un cos narratiu pobre. Molts es poden entendre simplement com a tradicions explicatives i, per tant, el tractament com a llegenda no es presenta prou clar. En destaquen dos que fan referència a sengles elements de la possessió d'Alfàbia, recollits al treball de Bàrbara Suau, Elisabet Abeyà i Gaspar Valero (2009) sobre les llegendes i tradicions bunyolines: «L'aljub de la reina mora» (2009: 26) i la «La cadira del rei Moro» (2009: 3I-34). Per altra part, Andreu Ferrer (2009: 267) cita el «Castellot de Moros» (sense especificar on es troba), una estructura ciclòpia prehistòrica però interpretada pels informants com una residència sarraïna. El mateix autor també cita el «Cementeri de Moros» (2009: 267), relacionat amb la troballa d'unes restes òssies en una possessió.

Abans d'acabar aquest apartat, cal dir que dins els diferents reculls toponímics fets a la serra de Tramuntana hi apareixen sovint topònims amb el determinant 
moro. En la majoria de casos aquests noms han quedat fossilitzats sense explicació de contingut. Molt possiblement, molts d'aquests noms remetien un temps a una narració o explicació, que malauradament no ens ha arribat avui dia. ${ }^{8}$

\subsection{Llegendes màgiques}

Jason defineix les llegendes màgiques com «a legend which tells of actions of humans possessing magic powers and of struggles between possessors of white and black magic. It is set in historical time (often the present) and in the space of "our district"» (2000: I46).

En aquest grup, els moros ja no es presenten com a enemics sinó com a coneixedors d'un saber ocult o prohibit per als cristians i col-laboren amb ells. Aquest tret té a veure amb el fet que pràctiques com l'astrologia, la fitoteràpia (fora dels àmbits monacals) o la localització d'aigües subterrànies (tècniques de saurí) eren considerades activitats heterodoxes, fins i tot herètiques. ${ }^{9}$ En aquest grup, de manera general, els moros apareixen com els que resolen conflictes o situacions adverses gràcies al seu coneixement i també perquè són els únics que poden posar en pràctica determinades activitats. Així mateix, tenen la capacitat de veure el futur en els estels, encara que l'avenir finalment no els sigui gens favorable.

Un dels millors exemples n'és «Es Moro cego» (Habsburg I982: 22I-226): un moro invident promet la llibertat a un esclau mallorquí si puja de dilluns a diumenge el puig de na Fàtima (Valldemossa) amb un parell de sabates diferents cada dia. El captiu ho fa i torna a Alger. El senyor es passa les sabates per davant els ulls i recobra la vista, tot gràcies a les herbes que hi havia trepitjat. L'allibera i el fa ric. Tot i les diverses claus simbòliques —explicades en la versió de Sabrafín «El Puig de na Fàtima» (I980: IO4)—, aquí el que interessa és que un moro no apareix com el temible enemic sinó com un coneixedor profund del poder curatiu de les plantes i, a més, es presenta com a exemple de paraula i honor. Aquest tret ve accentuat en la versió que en fa l'erudit valldemossí Juan Muntaner (I949: 8-9). A tall d'anècdota, aquesta mateixa llegenda es repeteix fora de l'àmbit de la serra de Tramuntana, al puig de Santa Cirga (Manacor), la qual cosa dona idea de la seva popularitat.

8 Bons exemples són l'era des Moro, molí des Moro (Banyalbufar), puig des Moro (Deià), cova des Moro (Sóller), penya des Moro (Escorca) o punta des Moro (Andratx). És interessant posar de relleu que tots aquests exemples pertanyen a municipis litorals.

9 A partir de la primera meitat del segle XVII, la Inquisició equipara certs usos de l'astrologia, considerada en època medieval com a una ciència, amb la fetilleria. Adelaida Sarrión, al seu treball Médicos e inquisición en el siglo XVII, afirma: «La proximidad entre ambos delitos [astrologia i fetilleria] refleja también el parecido intrínseco que, apara el inquisidor, había entre la práctica de la hechicería y la astrología» (2006: 85). Aquesta equiparació solia ser objecte d'investigació inquisitorial quan l'astrologia era practicada per una persona no culta, un esclau o un musulmà. Així, en el treball de L. Pérez, L. Muntaner i M. Colom El tribunal de la Inquisición en Mallorca. Relación de causas de fe. $1578-1806$ es recullen nombrosos interrogatoris on els investigats declaren que a voltes observen els estels amb la intenció de conèixer l'avenir. El més clar és el de Llorenç Fe, que confessà que «si tenia tiempo para mirar las estrellas antes de ponerse a la mar, no tenía miedo de peligro alguno» (I986: 80). 


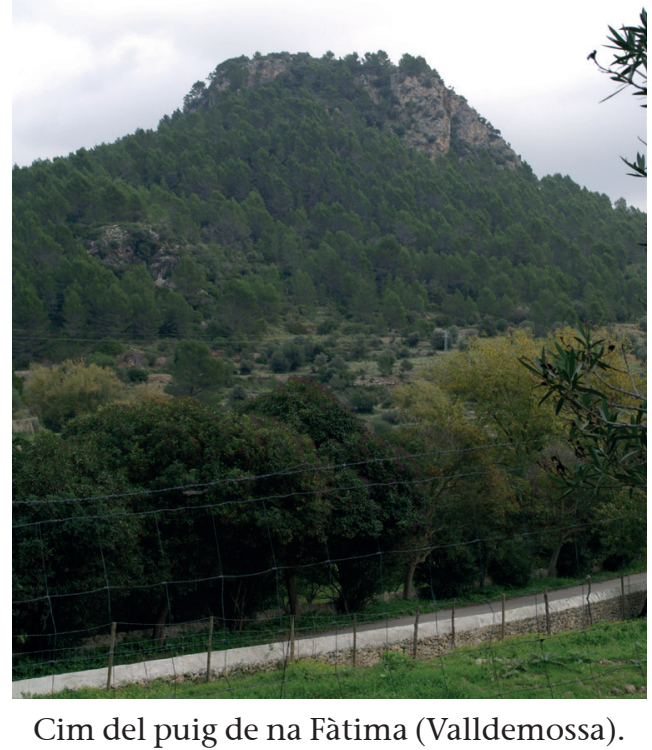

Un altre exemple en aquest context és «Una herba que deixaren es moros», arreplegada per Alcover (I976, XXIV: 83) de boca de mestre Antoni Barceló, de Puigpunyent. Era una herba que «cura qualsevol mal d'uis» i que només floreix «es dissabte de Sant Joan». La llegenda es troba situada, curiosament, dins l'àmbit del puig de na Fàtima, en aquest cas de Puigpunyent. Resulta també interessant observar com el motiu de la cura de les afeccions oculars es torna a repetir. Aquesta llegenda fou recollida també per les estudioses locals Catalina Pont i Maribel Font (I990: 29).

De sempre, l'aigua a Mallorca ha estat un bé escàs i localitzar un aqüífer saludable i cabalós era imprescindible per a la vida d'una possessió. Com hem dit, la troballa d'aigües subterrànies no fou ben vista en determinats moments per l'Església, fins al punt de situar els saurins dins el punt de mira de la Inquisició. Per això, moltes de les llegendes amb aquest motiu són protagonitzades per moros. L'erudit Juan Muntaner (I949: 9-II) recollí una versió de «Sa Font de Xorrigo» (Habsburg I982: I33-I43) situada en territori valldemossí, titulada «La Font des Polls (Pastoritx)». Davant l'escassetat d'aigua en la possessió, Amet, un esclau moro, demana la llibertat al propietari a canvi de la troballa d'una font. Ho fa, però el senyor allarga amb excuses l'alliberament. L'esclau, cansat de la falta de paraula del senyor, vol desbancar la font però el pastor de la possessió l'implora que li deixi un filet d'aigua per als animals, i així ho fa abans de fugir amb una nau corsària.

Una variant de l'anterior (encara que molt esgarrada) és «Es Moret de Galatzó», recollida per Catalina Pont i Maribel Font (I990: 36), on l'esclau no apareix com el trobador d'aigua sinó com qui, per venjança, hi deixa només un roll d'aigua per al pastor. La mateixa llegenda la retrobam a la finca de Son Fe, entre Sa Pobla i Alcúdia. 
A més dels coneixements de les aigües subterrànies, els moros també són capaços de preveure les pluges. En la llegenda «El cordoncillo de n'Amet», arreplegada de boca de la família Mas Xucla de Valldemossa, per Juan Muntaner (I949: I2-I5), un esclau moro de la possessió de la Torre demana la llibertat a canvi d'assegurar una bona collita. Fa llaurar els camps i sembra tota la llavor, malgrat la sequera i davant la incredulitat de tothom. Aquella nit plou i tot germina. Després d'anys d'haver estat alliberat, torna a Mallorca per avisar els seus antics amos d'un desembarcament corsari a Valldemossa i els dona un bolic amb un cordoncillo. ${ }^{\text {Io }}$

Una altra de les arts heterodoxes (màgiques) que posseïen els moros era la capacitat de veure el futur en els estels, fins i tot la imminent victòria del rei Jaume I. Un moro anomenat Alí llegeix en els estels que els cristians triomfaran i per això amaga un tresor al coll de la Palomera -Andratx - (Garrido I997: 33).

Tal com acabem de veure, el motiu del tresor amagat està molt relacionat amb la fugida dels sarraïns després de l'arribada del rei Jaume I. Per ventura, una de les llegendes amb argument més complex (i també molt literaturitzat) és «La cova des Ermassets», arreplegada per Bartomeu Llinàs i Caterina Martí (I996: 23-28). Un pastor del Verger (Esporles) coneix un moro, Abdul, que tenia una botija amb uns pergamins amb les indicacions per trobar un tresor en el fons de la cova des Ermassets. L'element màgic és, en aquest cas, no sols el pergamí (escrit per dues cares) sinó especialment totes les proves màgiques que el cercador haurà de superar fins arribar al tresor. A més d'aquest motiu, la narració es troba encapçalada per l'explicació de l'origen del tresor: quan el rei En Jaume desembarcà, un noble moro i dotze guerrers més sortiren de la ciutat per guardar el gran tresor dins la cova. El noble, que era mag, transformà els guerrers en ermassets, éssers que custodiarien el tresor. Guardà els pergamins i fugí.

El pergamí aquí funciona com les lletres en àrab de l'enteixinat de les cases d'Alfàbia (Bunyola) de la llegenda d'Alcover (I976, XXIV: 40), que porten les instruccions de com arribar al tresor guardat sota la clastra: «baix de ses bigues, hi ha unes lletres d'es moros, que diuen lo que han de fer per trobar tal tresor». Ara bé, aquesta llegenda la classifiquem com a demònica i, per tant, es tracta en l'apartat següent.

Com a conclusió, sovint al llegendari la màgia està identificada amb els moros, tant amb els que habitaven l'illa abans de la vinguda del monarca català com amb els que patiren captiveri. El binomi moro-màgia queda ben patent en aquesta llegenda contada per madò Maria des Carreter al folklorista Andreu Ferrer (2009: 176):

En el puig Vermell, dins el terme de la possessió de son Claret, hei ha moltíssimes marjades envoltant el puig i, just al capcurucull o cim, fa una marjadeta més petita al capdamunt de la qual diuen que hi ha un encantament. S'hi troben restes d'antiga edificació i ceràmica aràbiga, i molts diuen que era un casat de moros i que està encantat.

Io Un cordoncillo és una cadeneta d'or que les dones de la pagesia portaven penjada pel coll. 


\subsection{Llegendes demòniques}

Jason defineix les llegendes demòniques com aquelles «in which man confronts the world of demons, the latter being part of folk belief. This legend is set in "human (historical)" time ("our generation" or "last generation") and is spaces of "our settlement" and "our district"»(2000: I46). En el cas que a nosaltres ens interessa, considerarem demons els éssers que custodien els tresors amagats pels moros abans de la fugida de Mallorca el I229.

Les més significatives (per nombre i també per concreció) són les que envolten el puig de na Fàtima de Puigpunyent. Les diferents narracions (especialment les d'Alcover) parlen d'un tresor vinculat amb la filla del rei moro (Fàtima) i un ésser que actua de guardià — serp, bou, dimoni- (demon) que, en superar una prova o proves - procés iniciàtic-, es transforma en un munt de monedes.

La puigpunyentina madò Catalina Comes i Cladera contà a Alcover la llegenda «Es tresor d'es Puig de Na Fàtima» (I976, XXIV: 8-IO), la qual tot just al principi aporta la filiació de qui dona nom al puig: «Aquesta Fàtima era sa fia d'un rei moro que romangué encantada dins un penyal d'aquest puig», vora el qual hi havia un tresor «d'aquells que es qui los deixava escondits, no podia entrar en el cel, que qualcú no los hagués trobats». Com es veu, no hi ha relació explícita entre tresor i princesa mora, encara que es dona per feta. Deixant de banda altres aspectes analitzats per Caterina Valriu (20I7: 73-75), l'element demònic és aquí la serp que custodia el tresor, símbol profilàctic i alhora multisemàntic, però que en tot cas cal situar dins l'àmbit de les forces obscures de la naturalesa o dels submons (Revilla 2003: 398). Qui sigui capaç de seguir unes passes (resar tres parenostres), farà que aquella «serpota [...] com una torre de molí de vent» (I976, XXIV: Io) esclati fent un tro espantós per així convertir-se en un munt de monedes de vint.

«Un altre tresor en es Puig de Na Fàtima» va ser contada a Alcover (I976, XXIV: 43-45) per tres informadors: Gabriel Rosselló, l'escolà i l'escolana, tots tres de Puigpunyent. En la possessió de sa Coma — vora el puig de na Fàtima- hi ha una cova endomassada, on la filla del rei moro hi havia deixat un bou d'or que sortia cada dissabte de Sant Joan fent por al bestiar. Aquest esclataria en dobles de vint si qualcú era capaç de col·locar-li dues candeles enceses sobre les banyes i tres llesques de pa amb oli dins la boca. El demon que guarda el tresor ara és un bou (hem d'entendre brau), un animal poderós i espaordidor que en una ocasió fins i tot encalçà madò Pintada «fins an es Garrover de ses Sabates» (I976, XXIV: 43), vora el poble. ${ }^{\text {II }}$ La transformació de l'animal en tresor passa per una clara simbologia cristiana: col·locar espelmes (element litúrgic) sobre les banyes (element profà, símbol de poder) i inserir tres (Trinitat) llesques de pa (cos de Crist) dins la boca.

Una versió d'aquesta darrera —-molt més senzilla i esquemàtica- fou arreplegada per Catalina Pont i Maribel Font de boca de madò Catalina Sóller (I990: 84). Resulta interessant, però, ja que reforça aqueixa interpretació cristiana de què acabem de parlar, atès que a més dels ciris damunt les banyes s'havia de posar pa beneït a la boca de l'animal.

II Aquesta llegenda mostra un alt nivell de concreció toponímica: sa Coma, Son Fortesa, na Falguera o es Garrover de ses Sabates. Tots aquests noms són ben vius avui dia. 


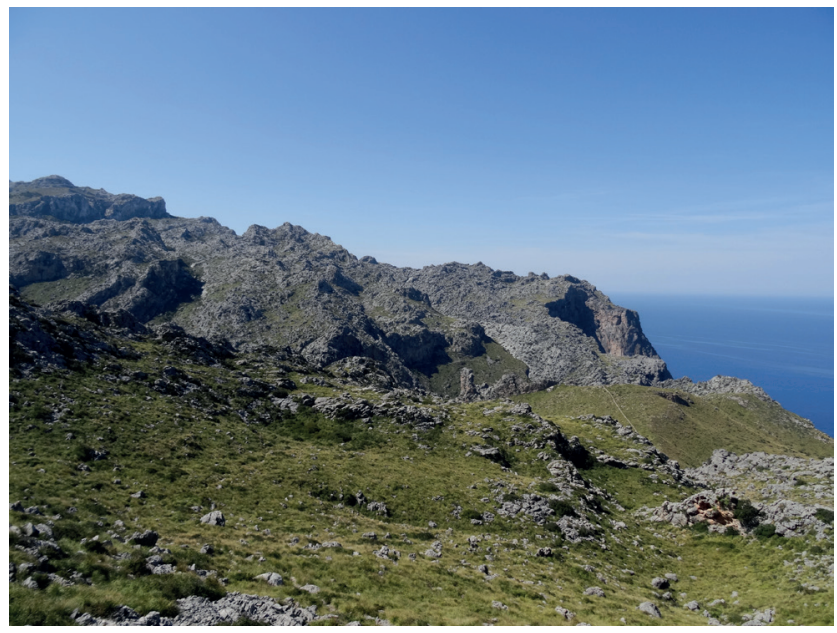

Entorn d'Ariant.

A la possessió bunyolina d'Alfàbia es dona un cas paral-lel de tresor amagat pels moros que és custodiat per un demon (aquí per un «dimoniot que fuma amb pipa»). «Es tresor d'Aufàbia», contada per l'amo En Lluc Batle, d'Orient, a Alcover (I976, XXIV: 4O-4I), presenta dues proves: en primer lloc, qui sigui capaç de llegir les lletres en àrab que hi ha a l'enteixinat del vestíbul de la possessió sabrà com accedir al tresor; i en segon, per evitar el dimoni guardià, «s'han de llevar tot lo beneït que duen damunt» (I976, XXIV: 4I). Com veiem, l'element sacre -cristià- hi apareix ara d'una forma molt explícita.

\section{Conclusions}

La proposta d'Heda Jason resulta una eina molt útil a l'hora de classificar el material llegendari mallorquí. Així mateix, a partir d'aquesta classificació modal se'n poden descartar molts relats que fins avui eren considerades llegendes pels reculls generalistes o locals, però que en realitat s'han d'encabir en el mode realista.

Pel que fa a resultats, un conjunt important de llegendes de la serra de Tramuntana se situa en l'àmbit de les narracions sacres. La capitalitat devocional de la Mare de Déu de Lluc, primer referent espiritual de Mallorca i també protectora davant els enemics de la fe, té una forta repercussió en el llegendari. D'aquí que les narracions amb la Mare de Déu que obra miracles davant dels moros que ataquen les costes i els vaixells mallorquins siguin molt nombroses i variades.

Dins l'apartat de llegendes sacres, però, es donen dos casos que no tenen com a argument un moro enemic, sinó que aquest és el que localitza una figura de la Mare de Déu en un lloc erm (Mare de Déu de Lluc i Mare de Déu del Cocó). En ambdós casos, es tracta d'un moro, fet que porta una forta càrrega simbòlica (la fe pura té el do de la visió celestial). Per tant, un nou cristià fa néixer una nova època.

Possiblement un temps les llegendes i les narracions etiològiques eren molt més nombroses i variades, atesa la gran quantitat de topònims amb el determinant moro que han quedat fossilitzats arreu de la Serra. Les narracions d'aquest gènere que foren transcrites pels recol-lectors se situen en dos àmbits: dins el temps 
dels moros (això és, abans de l'arribada del rei En Jaume), un espai que es revela com a quasi-mític, les quals solen tenir un alt component fabulós; i les protagonitzades per pirates que ataquen l'illa. La majoria explica l'origen d'un accident geogràfic relacionat amb un episodi protagonitzat per moros o en el qual hi intervingueren.

Les llegendes màgiques es troben majoritàriament capitalitzades per moros posseïdors de coneixements desconeguts o prohibits (o pseudo-prohibits) per als cristians (saurins, fitoteràpia, astrologia). Moltes d'aquestes pràctiques, si bé no es trobaven directament perseguides per l'Església, durant els segles de més repressió inquisitorial a Mallorca (segle XVI i sobretot XVII), sí que eren vigilades. Aquest és molt probablement un dels factors que explica per què en el folklore els moros n'eren els únics coneixedors.

Finalment, les llegendes demòniques — les menys nombroses — se centren en dos espais geogràfics molt concrets: el puig de na Fàtima (Puigpunyent) i la possessió d'Alfàbia (Bunyola). En ambdós casos, el demon és un animal (serp i bou) o un dimoni que preserva el tresor que els moros amagaren abans de fugir de l'illa. Per tant, el protagonista de l'acció és el cercador de tresors i no el moro, encara que el pes de la narració se centri en allò que amagaren els fugitius i quedà custodiat per unes forces màgiques.

En conjunt, les llegendes de la serra de Tramuntana ens presenten els moros en diversos papers, tots ells força delimitats i en alguns casos amb nombroses variacions: dels ferotges atacants de les costes illenques als posseïdors d'un domini «màgic» dels elements de la natura; dels luxuriosos habitants d'un castell cremat per gelosia a mostrar-se com un paradigma d'honor i paraula; dels que amaguen els seus tresors sota una muntanya abans de fugir de la terra natal a ser els més purs dels cristians.

\section{Apèndix. Relats en mode realista}

A continuació citem els títols de relats continguts en els diversos reculls de llegendes de la serra de Tramuntana que tenen com a protagonistes o coprotagonistes els moros. Distingim dos grans subgrups a partir del gènere: l'èpic i el novel-lístic.

\subsection{Gènere èpic}

«Un àguila i el rei en Jaume» (Alcover I976)

«Sa pica des Cavall del rei en Jaume» (Alcover I976)

«Sa primera missa en el Pantaleu» (Alcover I976)

«Desembarc del rei i ses tropes» (Alcover I976)

«Sa Pedra sagrada» (Alcover I976)

«El Puig del Rei» (Ferrà I976)

«L'enterrament dels germans Montcada» (Cortey I993)

«S'Avenc d'en Corbera» (Alcover I976)

«De com el rei en Jaume va prendre el castell d'Alaró» (Alcover I976)

«Es moros d'es Castellêt» (Habsburg I982)

«La nostàlgia del moro» (Sabrafin I980)

«Lo que succeí an es moros, una vegada, a Valldemossa» (Habsburg I982)

«Es pastor de s’Evangèlica» (anònim) 
«Valentes dones de Can Tamany» (Vidal I976)

«Venguda de Barba-rotja» (Ferrer 2009)

«Incursions pirates. La defensa de Son Mas» (Ferrer 2009)

Incursions de moros. Atacs a Pollença i Alcúdia (Ferrer 2009)

Amed de Can Beduia (Muntaner 1949)

Amet de Son Batista (Muntaner 1949)

«El puig de n’Escuder» (Janer I984)

\subsection{Gènere novel·lístic}

«Es Secret de na Fàtima» (Pont, Font I990)

«Fàtima» (Pont, Font I990)

«Troballa d'una alfàbia a Son Tries» (Llinàs, Martí I996)

«Les mines de Son Creus» (Suau, Abeyà, Valero 2009)

«La Rafal i la llegenda del tresor islàmic» (Bota I986)

«El carbó de Biniamar» (Ordinas 2002)

«Es patró esclau» (Habsburg I982)

«El tresor de la plaça d'Andratx» (Ferrer 2009)

«Bendinat» (Ferrer 2009)

«El forn del moro» (Capó, Morro 2007) 


\section{Referències bibliogràfiques}

Alcover, Antoni Maria (I976): Aplec de Rondaies Mallorquines d'en Jordi d'es Racó, toms V, XXIV. Palma: Editorial Moll.

- (I996-20I3): Rondaies mallorquines d'en Jordi des Racó. A cura de Josep A. GRIMALT amb la col-laboració de Jaume GuISCAFrè. I996 (vol. I), I998 (vol. II), $200 \mathrm{I}$ (vol. III), 2006 (vol. IV), 2009 (vol. V), 2013 (vol. VI). Ciutat de Mallorca: Moll.

AmADES, Joan (I950): Folklore de Catalunya. Rondallística. Barcelona: Editorial Selecta.

BAlañá, Pere (2003): Llegendes de moros i cristians. Col·lecció Nissaga, n. I7. Barcelona: Rafael Dalmau Editor.

BotA, Miquel (I986): Llegendes i tradicions. Palma: Edicions Cort.

BUSQUETS, Rafel (1989): Llibre de la invenció i miracles de la prodigiosa figura de nostra senyora de Lluc. Inca: Publicacions del Santuari de Lluc [facsímil de l'edició de I684].

Calafat, Catalina; Miquel Àngel Llauger; Joan Manuel Pérez (I985): «Pedres marcades». Palma: treball mecanografiat de 4t de Filologia Catalana.

CAMPS, Gabriel; Gabriel SEguí (20IO): La llegenda hagiogràfica de la invenció de la Mare de Déu de Lluc. Llibres de la Nostra Terra, 86. Palma: Lleonard Muntaner Editor.

CAPó, Josep; Mateu Morro (2007): Llegendes i rondalles santamarieres. Santa Maria: Ajuntament de Santa Maria del Camí.

Cortey, Maria Dolors (I993): Llegendes de les nostres terres. Barcelona: Publicacions de l'Abadia de Montserrat.

CostA, Miquel (I994): Obres completes. Mallorca: Fundació Antoni Maura / Fundació Rotger Villalonga.

FErRÀ, Miquel (I996): Llegendes i tradicions de les Balears. Palma: Edicions Documenta Balear.

Ferrer, Andreu (2009): Llegendes de les Balears. Barcelona: Publicacions de l'Abadia de Montserrat.

GARrido, Carlos (I997): Ruta de les llegendes de les Illes Balears. Palma: El Día del Mundo.

HAND, Wayland D. (1965): «Status of European and American legend study». Current Anthropology vol. 6, núm. 4: 439-446.

HABSburg, Lluís Salvador d'(1982) [1895]: Rondayes de Mallorca. Barcelona: José J. de Olañeta Editor.

JANER, Gabriel (I984): Les llegendes de les Terres de Lluc. Mallorca: Publicacions del Santuari de Lluc.

- (I999): Les festes llunyanes. Tradició i llegenda dels mallorquins. La Foradada, n. 63. Palma: José J. de Olañeta Editor.

JASON, Heda (2000): Motif, type and genre. Folklore Fellows Communications 273. Hèlsinki: Suomalainen Tiedeakatemia. 
LLINÀs, Bartomeu; Caterina MARTí (I996): Llegendes i tradicions d'Esporles. Llibres de la Nostra Terra, 22. Palma: Lleonard Muntaner Editor.

Muntaner, Juan (I949): Tradiciones y leyendas de Valldemossa. Palma: Impremta «Mossèn Alcover».

ORIOL, Carme (2002): Introducció a l'etnopoètica. Teoria i formes del folklore en la cultura catalana. Col-lecció Antines, 3. Valls: Cossetània.

— (20I3): «Le classement des récits étiologiques catalans». Dins Galina KABAKOVA (ed.): Contes et légendes étiologiques dans l'espace européen. Paris: Pippa/Flies France, p. 3I-45.

Oriol, Carme; Josep M. PujOL (2003): Índex tipològic de la rondalla catalana. Materials d'etnologia de Catalunya, 2. Barcelona: Generalitat de Catalunya.

Ordinas, Antoni; Gabriel Ordinas; Antoni Reynés (I998): El camí vell de Lluc. Palma: Sa Nostra / Consell de Mallorca / FODESMA.

PÉREz, Llorenç; Lleonard MuntAner; Mateu Colom (I986): El Tribunal de la Inquisión en Mallorca. Relación de causas de fe. I578-I806. Colección La Rodella, Io. Palma: Miquel Font Editor.

PONT, Catalina; Maribel Font (I990): Recull de narrativa popular (Puigpunyent-Galilea). Puigpunyent: Ajuntament de Puigpunyent.

Prohens, Bartomeu (I995): Inquisició i bruixeria a Mallorca (I578-I650). Llibres de la Nostra Terra, I7. Palma: Lleonard Muntaner.

Pujol, Josep M. (20I3): «Folklore narratiu: la rondalla i la llegenda». Dins Carme Oriol; Emili SAMPer (eds.): Això era i no era. Obra folklòrica de Josep M. Pujol. Tarragona: Publicacions URV, p. 277-287.

Revilla, Federico (2003) [I993]: Diccionario de iconografia y simbología. Madrid: Cátedra.

SABRAfÍn, Gabriel (I980): Mallorca: leyendas, tradiciones y relatos. Palma: Luis Ripoll Editor.

- (2002): El purgatori d'Ariant. Llegendes de les Balears, 2. Pollença: El Gall Editor.

SARrIón, Adelina (2006): Médicos e inquisición en el siglo XVII. Colección Monografías. Cuenca: Universidad de Castilla-La Mancha.

SuAU, Bàrbara; Elisabet ABEYÀ; Gaspar VALERo (2009): Tot pot ser en aquest món. Llegendes i contarelles de Bunyola i Orient. Magatzem Can Toni, 47. Palma: Documenta Balear.

Toponimia Mallorca. <https://www.toponimiamallorca.net/> [data de consulta: gener de 20I8].

VAlRIU, Caterina (2009): Llegendes de Mallorca. Barcelona: Publicacions de l'Abadia de Montserrat.

— (20I7): «Les llegendes del Puig de na Fàtima de Puigpunyent i el motiu del tresor amagat». Dins: IV Jornades d'Estudis locals de Puigpunyent. Puigpunyent: Ajuntament de Puigpunyent, p. 69-75.

VALRIU, Caterina; Tomàs VIBOT (2005): El rei En Jaume I: un heroi històric, un heroi de llegenda. La Foradada, Io9. Palma: José J. de Olañeta Editor.

VIDAL I Alcover, Jaume (I978): Recull de llegendes. Barcelona: Dopesa. 